\title{
KEELE ASEND EESTI PALATALISATSIOONIS
}

\author{
Anton Malmi ja Pärtel Lippus \\ Tartu Ülikool
}

\begin{abstract}
Ülevaade. Artiklis uuritakse palatalisatsiooni mõju konsonandi ja talle eelneva vokaali häälduskohale ja kestusele. Katse viidi läbi elektromagnetartikulograafi abil, mis mõõdab katseisiku artikulaatoritele liimitud sensorite liikumist kolmemõõtmelises ruumis. Tulemused näitasid, et palataliseerimisega kaasnes konsonandi ja talle eelneva vokaali hälaldamisel keele kõrgem ja eespoolsem asend. Keele eesosa kõrgus oli vähesel määral palatalisatsioonist mõjutatud, kuid kõrguse muutumine ei olnud süsteemne. Tulemused ei näidanud palatalisatsiooni süstemaatilist efekti ka konsonandi ja talle eelneva vokaali kestusele. Ainult üksikutel juhtudel pikenes hääliku kestus palataliseeritud kontekstis olulisel määral.
\end{abstract}

Märksõnad: artikulatoorne foneetika, eksperimentaalne foneetika, hääldamine, palatalisatsioon, eesti keel, kestus, Carstens AG501

DOI: https://doi.org/10.12697/jeful.2019.10.1.06

\section{Sissejuhatus}

Artikli eesmärk on uurida, kuidas mõjutab eesti keele palatalisatsioon alveolaarsete konsonantide $/ \mathrm{s} /, / \mathrm{t} /, / \mathrm{n} /, / 1 /$ ja neile eelnevate vokaalide häälduskohta ja kestust. Artikulatoorselt on palatalisatsioon koartikulatoorne protsess, kus konsonandi primaarsele häälduskohale (/s/-i, /t/, /n/-i ja /1/-i puhul alveoolidel) lisandub sekundaarne häälduskoht kõval suulael. Viimast nimetatakse sekundaarseks palatalisatsiooniks (Bateman 2007). Selle foneetilise protsessi põhjustab konsonandile järgnev vokaal/i/ või poolvokaal/j/. Koartikulatsiooni tulemusel assimileeruvad konsonandi ja talle järgneva hääliku häälduskohad, mõjutades sellega konsonandi häälduskohta ja -viisi (Bateman 2007). Teisalt on eesti keeles palatalisatsioon mõnes sõnatüübis varieeruv, valikuline ning see, kas palataliseeritakse või mitte, sõltub piirkonnast ja kõnelejast (Piits ja Kalvik 2019, Põld 2016 ning Teras ja Pajusalu 2014). Näiteks võib sõna album häälduda ilma palatalisatsioonita [al:pum] või 
palataliseeritult [alj:pum], kuid palatalisatsioon ei erista siin tähendust, vaid peegeldab kõneleja idiolekti.

Eesti keeles on palatalisatsioon ka fonoloogiliselt kontrastiivne ehk seda saab kasutada tähenduse eristamiseks fonoloogilistes paarides (palk sg nom [palk:] palk sg nom [palik:]). Selline eristus ei kajastu sõnade ortograafias ning tähenduse mõistmiseks peab lugeja aru saama kontekstist, milles sõna esineb. Niisugused paarid on tekkinud tänapäevasesse eesti keelde enamasti lõpukao tagajärjel (Kask 1972: 118): nominatiivi vormis on tüvevokaal kadunud, kuid $i$-tüvelistes sõnades on konsonant endiselt palataliseeritud, muu tüvevokaali puhul palatalisatsiooni ei esine. Siiski võivad lõpukao tõttu mõnel juhul palataliseeruda ka $e$-tüvelised sõnad, nt sulg sg nom [sulj:k]. Eesti keele kontrastiivne palatalisatsioon realiseerub konsonandi hääldamisel ühesilbilises sõnas pärast esimest vokaali ja kahesilbilises sõnas esimese rõhulise ja teise rõhutu silbi piiril (Kask 1972: 118 ning Teras ja Pajusalu 2014).

Sekundaarse palatalisatsiooni peamine keelteülene artikulatoorne tunnus on keeleselja tõus kõva suulae poole (Bateman 2007). Akustiliselt avaldub keeleselja tõus vokaalide puhul hästi teise formandi (F2) väärtuses, mis on keeleselja eespoolsema asendi ja kõrgema tõusuastme tõttu suurem. Iseloomulik on ka esimese formandi (F1 - keele kõrgus ja neeluõõne avatus) ja kolmanda formandi ( $\mathrm{F} 3$ - huulte ümardatus) väärtuste muutumine, kuid see ei ole nii ulatuslik ja süsteemne kui F2 puhul. Seetõttu on käesolevas uurimuses keskendutud eeskätt palatalisatsioonist mõjutatud F2 väärtuste analüüsile. Konsonantide uurimisel saab formantanalüüsi kasutada ainult sonoorsete häälikute puhul, sest näiteks frikatiividel ja klusiilidel pole selget formantstruktuuri. Konsonantidele eelnevatel vokaalidel on modaalse kõne korral selge formantstruktuur olemas. Seetõttu on tavaliselt palatalisatsiooni kirjeldustes keskendutud vokaalilt konsonandile liikuva siirde analüüsimisele.

Siiret analüüsinud uurijad on leidnud (Chiosáin ja Padgett 2012 Connemara iiri keele kohta, Lehiste 1965 ja Liiv 1965a, 1965b eesti keele kohta, Derkach et al. 1970, Howie 2001 ja Purcell 1979 vene keele kohta, Vihman 1967 vene ja eesti keele kohta), et vokaali lõpus, siirdel konsonandile, toimub palataliseerimisel ulatuslik F2 väärtuse tõus. See viitab keeleselja tõusule. Sama on kinnitatud ka artikulatoorsetes uurimustes (Ariste 1943, Eek 1971, 1973, Kutser 1935 ning Meister ja Werner 2015). F2 tõusu ulatus sõltub vokaalist ja talle järgneva konsonandi kvaliteedist. Tagapoolsema ja madalama häl̈lduskohaga vokaali hääldamisel peab 
keel läbima pikema tee, et jõuda palatalisatsiooni tekitamiseks sihtpunkti (Eek 1973 ja Lehiste 1965). Palataliseerimisega kaasnev keeleselja tõus vokaali lõpuosas toob kaasa ka vokaali kestuse pikenemise (Lehiste 1965, Liiv 1965a ning Teras ja Pajusalu 2014), konsonandi kestuse pikenemise kohta teadaolevalt andmeid ei ole.

Varasemalt on palatalisatsiooni kirjeldustes keskendutud vokaali lõpuosas toimuvale ulatuslikule F2 tõusule ning on märgitud, et hälduskoha muutus kajastub ka konsonandi akustilises kvaliteedis. /1/-i ja /n/-i häälduses võib küll näha F2 väärtust tõstvat palatalisatsiooni efekti (Eek 1972 ja Lehiste 1965), kuid /n/-i puhul on palatalisatsiooni mõju väga nõrk, sest nasaali hääldamisel tekib ninaõõnes antiformant, mis summutab F2 väärtust. /1/-i puhul tekib antiformant keeletipu taha, kuid sinna ei neeldu nii palju energiat kui ninaõõnde. Spektraalse energia keskmine väärtus on palataliseeritud /s/-i, /t/ ja /n/-i hääldamisel madalam, kuid /1/-i hääldamisel kõrgem (Malmi 2019). Selle suurenemist ja vähenemist seostatakse keele ees- ja tagapoolsusega ning ka sellega, kui suure pingutuse me peame hääldamiseks tegema. Malmi (2019) tulemused viitasid mõningate reservatsioonidega sellelegi, et palatalisatsioon ei mõjuta konsonandi kvaliteeti ainult algusosas, vaid kogu hääliku ulatuses. Eek (1973) väitis, et peamist palatalisatsiooniinfot kannavad palataliseeritud konsonandile eelneva vokaali lõpus olev siire ja konsonandi algusosa kvaliteedi muutus. See, et ka konsonandi teises osas võib kvaliteedimuutust näha, on seotud talle järgneva vokaaliga, mitte palatalisatsioonist tingitud mõjuga.

Kui konsonantide häälduskohti võrreldi palatograafi abil, siis selgus, et palataliseeritud /s/-i hääldamisel on ülemiste hammaste taga alveoolil olev ahtus, kust õhk välja pääseb, kitsam, kuid keele külgede kontaktala hammastel on nii palataliseeritud kui ka palataliseerimata /s/-i puhul sarnane (Ariste 1943 ja Kutser 1935). Palataliseeritud /t/ häälduskoht on tagapoolsem kui palataliseerimata $/ \mathrm{t} / \mathrm{-1}$ ning palataliseeritud $/ \mathrm{t} / \mathrm{-1}$ on alveoolil keele laiem toetusala ja suurem keele külgede kontaktala hammastel (Ariste 1943 ja Kutser 1935). Samu tulemusi saadi ka poola ja vene keele kohta (Kochetov 2002 ning Zygis ja Pompino-Marschall 1999). Palataliseeritud /n/-i iseloomustab laiem keeletipu kontaktala postalveoolil ja keele külgede laiem kontaktala hammastel (Ariste 1943, Kutser 1935 ning Meister ja Werner 2015), kuid mitte eespoolsem häälduskoht, nagu Eek (1971) seda leidis olevat. Palataliseeritud /1/-i iseloomustab eespoolsem ja laiem keeletipu kontakt alveoolil ja 
postalveoolil ning laiem keele külgede kontakt hammastel (Ariste 1943 ja Eek 1971). Meister ja Werner (2015) ei saanud enda andmete põhjal palataliseeritud /1/-i eespoolsemat häälduskohta kinnitada. Kõikide konsonantide puhul täheldati, et välte suurenedes suurenes ka kontakt suulael (Ariste 1943, Eek 1970, 1971 ning Meister ja Werner 2015). Seda, kui suur on kontaktala suulael, mõjutas ka kõnetempo: kiirema tempoga oli kontakt väiksem (Barry 1992).

Käesolevas uurimuses kasutati elektromagnetartikulograafi (EMA), et anda dünaamiline ülevaade palatalisatsiooni mõjust keele liikumisele eesti keele alveolaarsete konsonantide hääldamisel. Analüüsiti keeleselja tõusuastet ning selle ees- ja tagapoolsust suuõõnes, kuid mitte keele kontakti suulaega. Palatograafia on küll hea meetod uurimaks keele kontakti suulaega, kuid keel ei puuduta suulage kõikide oma osadega. Keele täpse asendi kohta suus annab EMA paremat infot kui palatograafiaga. Seepärast ei ole käesoleva uurimuse tulemused üheselt võrreldavad varasemate palatograafial põhinevate tulemustega, kuid on hädavajalikuks täienduseks tervikpildi loomisel.

Käesolevas artiklis otsiti vastust järgmistele küsimustele:

a. kuidas mõjutab palatalisatsioon keeleselja asendit ja kui ulatuslik on see mõju vokaali ja konsonandi järjendile ajaliselt? Varasematele uurimustele tuginedes oleks ootuspärane eeldada, et kõige tugevam on palatalisatsiooni mõju vokaali lõpuosas ning konsonandi alguses;

b. kas palatalisatsioon mõjutab konsonandi ja talle eelneva vokaali kestust? Varasemad uurimused on näidanud, et palataliseeritud konsonandile eelnev vokaal pikeneb $i$-lise siirde võrra. Konsonandi puhul võiks oodata vokaali pikenemise tõttu kompensatoorset lühenemist, millele küll varasemas kirjanduses viited puuduvad.

\section{Materjal ja meetod}

Katse viidi läbi Tartu Ülikooli foneetika laboris. Katses osales 21 keelejuhti (10 meest, 11 naist). Katseisikud lugesid arvutiekraanilt juhuslikus järjekorras esitatud lauseid. Katse läbiviimiseks saadi Tartu Ülikooli inimuuringute eetikakomitee nõusolek 277/T-2.

Selleks et uurida eesti keele palatalisatsiooni artikulatoorseid tunnuseid, valiti stiimulsõnadeks 30 minimaalpaari täistähenduslikest sõnadest, mis erinesid ainult esisilbi koodakonsonandi palataliseerituse poolest. Enamik stiimuleid olid ühesilbilised lühikese vokaali 
ja pika konsonandi või konsonantühendiga sõnad, kuid oli ka üksikuid kahesilbilisi lühikese vokaaliga teise- või kolmandavältelisi sõnu. 60 stiimulsõna olid paigutatud raamlause fraasilõpulisse positsiooni, näiteks „Kevadel sündis väike tall, mitte vasikas”, „Hobustele ehitati uus tall, mis pakub neile peavarju kogu aasta".

Artikulatsiooniandmed salvestati artikulograafiga Carstens AG501. Artikulograaf töötab elektromagnetvälja põhimõttel. Masin leiab katseisiku ülakeha ümber olevas magnetväljas erinevatel sagedustel võnkuvate sensorite asukoha (millimeetrites) kolmemõõtmelises ruumis ja nende pöördenurga oma telje ümber. Artikulaatoritele liimitud sensorite liikumine salvestati kvantimissagedusega $200 \mathrm{~Hz}$. Iga salvestussessiooni alguses pandi katseisikule korraks suhu kolme sensoriga plaat, mis normaliseerib sensorite abil koordinaadid nii, et nullpunkt on katseisiku keha keskjoonel ja hammaste lõikejoonel. Katseisiku keeleseljale liimiti ristikujuliselt 10-millimeetriste vahedega viis sensorit: 1. taha keele keskjoonele, 2. keele keskjoone keskele, 3. keele keskossa $10 \mathrm{~mm}$ keskjoonest paremale, 4. keele keskossa $10 \mathrm{~mm}$ keskjoonest vasakule ja 5.keele keskjoonele umbes $5 \mathrm{~mm}$ keele tipust. Lisaks liimiti 6. sensor alumisele igemele esihammaste alla, et mõota lõualuu liikumist. Sensorite skemaatilist paigutust illustreerib joonis 1. Katse läbiviija jälgis pidevalt ekraanilt sensorite liikumist ning kui mõni sensor tuli lahti, siis liimis selle tagasi ning lasi katseisikul lause uuesti lugeda.

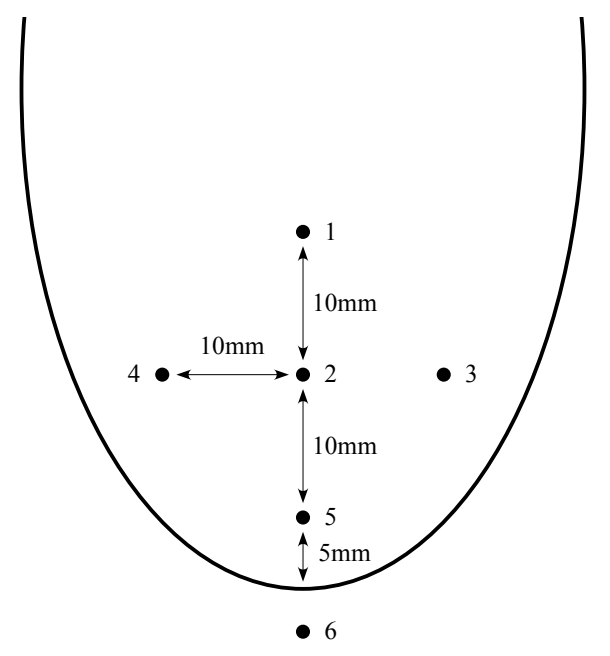

Joonis 1. Skemaatiline kujutis sensorite asukohtadest keelel ja igemel. Numbrid 1-6 viitavad sensorite järjekorranumbritele. 
Lisaks EMA sensoritele salvestati ka akustiline helisignaal. Akustilisi salvestisi kasutati, et leida häälikute algus- ja lõpuajad. Häälikupiiride leidmiseks kasutati Tallinna Tehnikaülikooli automaatsel kõnetuvastusel põhinevat autosegmenteerijat (Alumäe et al. 2018). Automaatselt segmenteeritud helifailid kontrolliti Praatis (Boersma ja Weenink 2019) käsitsi üle ja vajaduse korral tehti parandusi. Akustilistest salvestistest leitud häälikupiirid viidi kokku helifailidega sünkroniseeritud EMA salvestistega. Kõigi salvestatud sõnade hääldust kontrolliti kuuldeliselt ja analüüsist jäeti välja ebasobivad hääldusjuhud. Näiteks esines väga palju palataliseerimist sõnas õlg [rl:k] 'kehaosa' ja mittepalataliseerimist sõnas $\tilde{o l g}\left[\gamma^{\mathrm{j}} \mathrm{k}\right.$ k] 'teravilja kõrs'. Kuna selline hääldus ei vastanud ootustele, jäeti see paar analüüsist välja. Vahel ei andnud ka kontekst piisavalt hästi ette õiget hääldusviisi või oli katseisikule sõna võõras (näiteks kott [kot:] 'puidust jalats') ning needki paarid jäid analüüsist välja. Kõik EMA salvestised kontrolliti visuaalselt üle. Välja jäeti need hääldusjuhud, mille korral esines sensorite signaalis häireid (näiteks kui mõni sensor oli lahti tulnud ja katse läbiviija ei pannud seda piisavalt kiiresti tähele).

Käesolevas uurimuses analüüsiti lühikese vokaali ja pika konsonandiga (CVC:) sõnu, mida oli kokku 11 sõnapaari. Pärast andmete puhastamist ja kontrollimist jäi analüüsitud materjali 431 hääldusjuhtu. Analüüsis kasutatud katsesõnad on esitatud tabelis 1 ja kasutatud laused on ära toodud lisas 1 .

Tabel 1. Analüüsis kasutatud katsesõnad, milles palatalisatsioon eristab tähendust.

\begin{tabular}{lcccc}
\hline & /l/ & /n/ & /s/ & $/ \mathbf{t} /$ \\
\hline /a/ & Mall/mall, tall, hall & kann & kas/kass & - \\
/o/ & - & on/onn & - & kott \\
$/ \mathbf{u} /$ & mul/mull & - & kus/kuss & nutt, Rutt/rutt \\
\hline
\end{tabular}

Käesolevas uurimuses kasutati andmeid kolmelt keele keskjoonel olevalt sensorilt. 1. sensori põhjal hinnati keeleselja tagaosa kõrgust, 5. põhjal keeleselja eesosa kõrgust ning 2. põhjal keeleselja eespoolsust. Statistiline analüüs tehti programmiga R (RStudio Team 2019). Keeleselja liikumise trajektooride hindamiseks vokaali ja konsonandi hääldamisel kasutati üldistatud aditiivset segamudelit (Generalized Additive 
Mixed Model e GAMM) mgcv paketist (Wood 2017). Andmed aegnormaliseeriti ja iga hääliku trajektoorist võeti 100 võrdse vahega mõõtmispunkti. Mudel hindas vastava sensori liikumistrajektoori nii palatalisatsiooni, vokaali- kui ka konsonandikategooria suhtes. Vokaalide ja konsonantide kestuse uurimiseks kasutati lineaarset segamudelit lme4 paketist (Bates et al. 2015), mis hindas kestuse muutumist samuti nii palatalisatsiooni, vokaali- kui ka konsonandikategooria suhtes. Kestusandmed logaritmiti, et lähendada nende jaotust normaaljaotusele. Selleks et leida võrdluspaarid, tehti lineaarsele mudelile post hoc test paketiga multcomp (Hothorn et al. 2008). Kõikide post hoc testide läbiviimisel kohandati $p$-väärtuseid Bonferroni-Holm meetodil.

\section{Tulemused}

Järgnevalt analüüsiti keeleselja tagaosa ja eesosa kõrgust (vastavalt sensorite 1 ja 5 põhjal) ning keele eespoolsust (sensori 2 põhjal). Joonistel 2-5 kujutatakse keeleselja kõrgust ja eespoolsust vokaali ja konsonandi hääldamisel üle kõigi keelejuhtide andmete keskmistatud väärtuste põhjal. Tabelitesse $2-9$ on koondatud kokkuvõtted üldistatud aditiivse segamudeli väljunditest: sensorite asukohtade prognoositud väärtused millimeetrites, nende standardvead, kahe häälduskonditsiooni erinevuste statistilised hinnangud ja mudelite kirjeldusvõime hinnangud ehk determinatsioonikordajad. 


\subsection{Palatalisatsiooni mõju vokaalide ja /s/-i hääldusele}

Joonisel 2 on kujutatud vokaalide /a/ ja /u/ ning neile järgneva /s/-i häälduskontuurid, tabelites 2 ja 3 on esitatud statistiliste mudelite väljundite kokkuvõtted vokaalide ja konsonantide kohta. Tabelitest 2 ja 3 näeme, et mudelite kirjeldusvõime jäi vahemikku 93-97\%. Analüüsitud sõnade alguses oli esimene konsonant kõikidel juhtudel /k/.
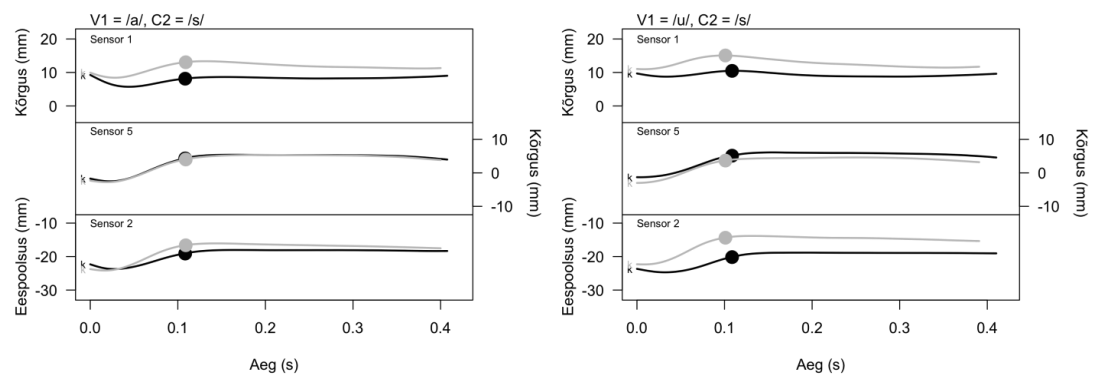

Joonis 2. Keele tagaosa (sensor 1) ja eesosa (sensor 5) kõrgus ning keele eespoolsus (sensor 2, millimeetrites hammaste lõikejoone suhtes) vokaali ja sellele järgnenud konsonandi /s/ hääldamise vältel. Musta joonega on tähistatud palataliseerimata, halliga palataliseeritud sõnad. Kontuurjoonte ees on tähega tähistatud sõna alguskonsonant. Ring joonel tähistab häälikupiiri vokaali ja konsonandi vahel.

Palataliseeritud /s/-i ees oleva vokaali hääldamise vältel oli keele tagaosa keskmiselt kõrgemal kui palataliseerimata /s/-i kontekstis $(p<0,001)$. Keele eesosa keskmine kõrgus vokaali /a/ hääldamisel palatalisatsiooni mõjul ei muutunud $(p=0,44)$. Vokaali $/ \mathrm{u} /$ hääldamisel oli keele eesosa palataliseeritud konsonandi ees madalam $(p<0,001)$ kui palataliseerimata konsonandi ees. Keele keskosa, ja seega kogu keel, oli $/ \mathrm{a} / \mathrm{ja} / \mathrm{u} /$ hääldamisel palatalisatsiooni korral eespoolsem $(p<0,001)$. 
Tabel 2. Kokkuvõte üldistatud aditiivse segamudeli väljunditest keele liikumise kohta (millimeetrites) /s/-ile eelneva vokaali hääldamisel.

\begin{tabular}{llcrrrrrr}
\hline V1 & $\mathbf{C 2}=/ \mathbf{s} /$ & $\begin{array}{c}\text { Palatali- } \\
\text { seerimata }\end{array}$ & $\begin{array}{c}\text { St. } \\
\text { viga }\end{array}$ & $\begin{array}{c}\text { Palatali- } \\
\text { seeritud }\end{array}$ & $\begin{array}{c}\text { St. } \\
\text { viga }\end{array}$ & Vahe & $p$ & $\mathbf{R}^{2}$ \\
\hline /a/ & Tagaosa kõrgus & 6,9 & 0,66 & 10,2 & 0,30 & 3,3 & $<0,001$ & 0,941 \\
& Eesosa kõrgus & 0,1 & 0,96 & 0,4 & 0,30 & 0,4 & 0,411 & 0,924 \\
& Keskosa eespoolsus & $-22,0$ & 1,67 & $-20,7$ & 0,37 & 1,3 & $<0,001$ & 0,972 \\
\hline /u/ & Tagaosa kõrgus & 9,0 & 0,66 & 12,7 & 0,30 & 3,7 & $<0,001$ & 0,941 \\
& Eesosa kõrgus & 1,1 & 0,96 & 0,0 & 0,30 & 1,1 & $<0,001$ & 0,924 \\
& Keskosa eespoolsus & $-23,0$ & 1,67 & $-19,5$ & 0,37 & 3,5 & $<0,001$ & 0,972 \\
\hline
\end{tabular}

Märkus. Tabelis on esitatud mudeli prognoositud väärtused ja standardvead (st. viga) vastavalt palataliseerimata ja palataliseeritud sõnades. Post hoc testi põhjal on välja toodud palatalisatsiooni efekti suurus (vahe) ning statistiline olulisus ( $p$ ). Mudeli üldist kirjeldusvõimet näitab determinatsioonikordaja $\left(\mathrm{R}^{2}\right)$.

Palataliseeritud /s/-i häälduskoht oli võrreldes palataliseerimata variandiga hääldatud kõrgema keeleselja asendiga (mõlema vokaalikonteksti puhul $p<0,001)$. Keele eesosa kõrgus vokaali /a/ kontekstis palataliseeritud /s/-i hääldamisel ei muutunud $(p=0,104)$, kuid oli /u/ kontekstis madalam $(p<0,001)$. Keele keskosa oli mõlema vokaali kontekstis palataliseeritud /s/-i hääldamisel eespoolsem kui palataliseerimata $/ \mathrm{s} /-\mathrm{i}$ puhul $(\operatorname{mõlemad} p<0,001)$.

Tabel 3. Kokkuvõte üldistatud aditiivse segamudeli väljunditest keele liikumise kohta (millimeetrites) /s/-i hääldamisel

\begin{tabular}{llccccccc}
\hline V1 & $\mathbf{C 2}=/ \mathbf{s} /$ & $\begin{array}{c}\text { Palatali- } \\
\text { seerimata }\end{array}$ & $\begin{array}{c}\text { St. } \\
\text { viga }\end{array}$ & $\begin{array}{c}\text { Palatali- } \\
\text { seeritud }\end{array}$ & $\begin{array}{c}\text { St. } \\
\text { viga }\end{array}$ & Vahe & $p$ & $\mathbf{R}^{2}$ \\
\hline /a/ & Tagaosa kõrgus & 8,5 & 0,72 & 12,1 & 0,37 & 3,6 & $<0,001$ & 0,958 \\
& Eesosa kõrgus & 5,1 & 0,98 & 4,6 & 0,28 & 0,5 & 0,104 & 0,937 \\
& Keskosa eespoolsus & $-18,2$ & 1,72 & $-16,4$ & 0,38 & 1,8 & $<0,001$ & 0,976 \\
\hline /u/ & Tagaosa kõrgus & 9,0 & 0,72 & 12,7 & 0,37 & 3,7 & $<0,001$ & 0,958 \\
& Eesosa kõrgus & 5,5 & 0,98 & 4,4 & 0,28 & 1,1 & $<0,001$ & 0,937 \\
& Keskosa eespoolsus & $-18,7$ & 1,72 & $-15,0$ & 0,38 & 3,8 & $<0,001$ & 0,976 \\
\hline
\end{tabular}

Märkus. Tabelis on esitatud mudeli prognoositud väärtused ja standardvead (st. viga) vastavalt palataliseerimata ja palataliseeritud sõnades. Post hoc testi põhjal on välja toodud palatalisatsiooni efekti suurus (vahe) ning statistiline olulisus ( $p$ ). Mudeli üldist kirjeldusvõimet näitab determinatsioonikordaja $\left(\mathrm{R}^{2}\right)$. 


\subsection{Palatalisatsiooni mõju vokaalide ja /t/ hääldusele}

Joonisel 3 on kujutatud vokaalide /o/ ja / $/$ / ja neile järgneva konsonandi / $t$ / häälduskontuurid ning tabelites 4 ja 5 on esitatud statistiliste mudelite väljundite kokkuvõtted. Tabelitest 4 ja 5 näeme, et mudelite kirjeldusvõime jäi vahemikku $85-96 \%$. Vokaali /o/ kontekstis oli analüüsitud sõnade alguses esimene konsonant $/ \mathrm{k} / ; / \mathrm{u} /$ kontekstis kas $/ \mathrm{r} /$ või $/ \mathrm{n} /$. Sõna alguskonsonandi varieerumist ei ole statistilistes mudelites arvestatud, kuid on tähistatud joonistel.
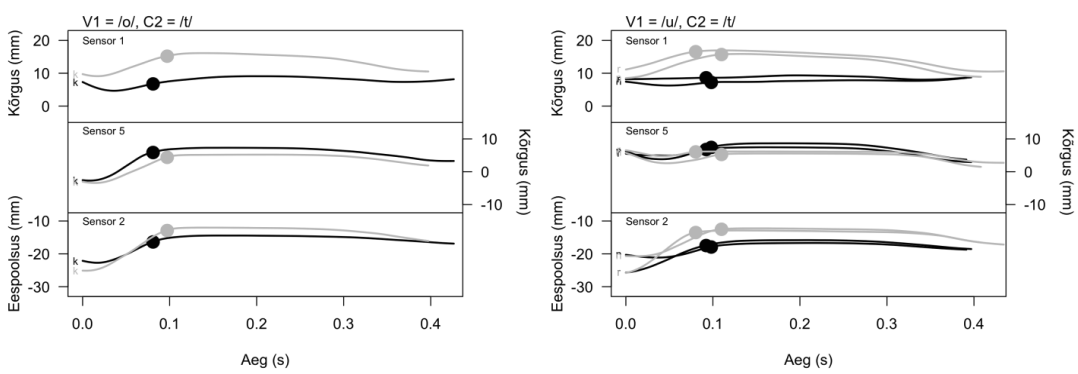

Joonis 3. Keele tagaosa (sensor 1) ja eesosa (sensor 5) kõrgus ning keele eespoolsus (sensor 2, millimeetrites hammaste lõikejoone suhtes) vokaali ja konsonandi /t/ hääldamise vältel. Musta joonega on tähistatud palataliseerimata, halliga palataliseeritud sõnad. Kontuurjoonte ees on tähega tähistatud sõna alguskonsonant. Ring joonel tähistab häälikupiiri vokaali ja konsonandi vahel.

Vokaali hääldamisel oli keele tagaosa palataliseeritud /t/ kontekstis kõrgem kui palataliseerimata /t/ puhul (/o/-1 ja /u/-1 mõlemal on $p<0,001)$. Vokaali /o/ hääldamisel oli keele eesosa enne palataliseeritud $/ \mathrm{t} / \mathrm{d}$ madalamal $(p<0,005)$ kui enne palataliseerimata $/ \mathrm{t} /$-d, kuid /u/ hääldamisel mitte $(p=0,257)$. Keele keskosa oli mõlema vokaali hääldamisel enne palataliseeritud $/ \mathrm{t} / \mathrm{d}$ eespoolsem (mõlemal on $p<0,001)$ kui enne palataliseerimata $/ \mathrm{t} / \mathrm{d}$. 
Tabel 4. Kokkuvõte üldistatud aditiivse segamudeli väljunditest keele liikumise kohta (millimeetrites) /t/-le eelneva vokaali hääldamisel.

\begin{tabular}{llrrrrrrr}
\hline V1 & \multicolumn{1}{c}{$\mathbf{C 2}=/ \mathbf{t} /$} & $\begin{array}{c}\text { Palatali- } \\
\text { seerimata }\end{array}$ & $\begin{array}{c}\text { St. } \\
\text { viga }\end{array}$ & $\begin{array}{c}\text { Palatali- } \\
\text { seeritud }\end{array}$ & $\begin{array}{c}\text { St. } \\
\text { viga }\end{array}$ & Vahe & $p$ & $\mathbf{R}^{2}$ \\
\hline /o/ & Tagaosa kõrgus & 5,4 & 0,61 & 11,4 & 0,49 & 6,0 & $<0,001$ & 0,848 \\
& Eesosa kõrgus & 1,0 & 0,89 & $-0,4$ & 0,46 & 0,6 & $<0,005$ & 0,871 \\
& Eespoolsus & $-22,1$ & 1,61 & $-19,8$ & 0,45 & 2,3 & $<0,001$ & 0,913 \\
\hline /u/ & Tagaosa kõrgus & 7,6 & 0,61 & 13,0 & 0,49 & 5,6 & $<0,001$ & 0,848 \\
& Eesosa kõrgus & 5,2 & 0,89 & 4,7 & 0,46 & 0,5 & 0,257 & 0,871 \\
& Keskosa eespoolsus & -21 & 1,61 & $-18,9$ & 0,45 & 2,1 & $<0,001$ & 0,913 \\
\hline
\end{tabular}

Märkus. Tabelis on esitatud mudeli prognoositud väärtused ja standardvead (st. viga) vastavalt palataliseerimata ja palataliseeritud sõnades. Post hoc testi põhjal on välja toodud palatalisatsiooni efekti suurus (vahe) ning statistiline olulisus $(p)$. Mudeli üldist kirjeldusvõimet näitab determinatsioonikordaja $\left(\mathrm{R}^{2}\right)$.

Palataliseeritud /t/ häälduskoht oli võrreldes palataliseerimata variandiga kõrgema keeleselja asendiga $(p<0,001$ nii /o/ kui ka /u/ kontekstis), keele eesosa oli madalam $(p<0,001)$ ja keele keskosa oli eespoolsem $(p<0,001)$.

Tabel 5. Kokkuvõte üldistatud aditiivse segamudeli väljunditest keele liikumise kohta (millimeetrites) /t/ hääldamisel.

\begin{tabular}{llrrrrrrr}
\hline V1 & C2 $=/ \mathbf{t} / \mathbf{P a l a t a l i -}$ & $\begin{array}{c}\text { St. } \\
\text { seerimata }\end{array}$ & $\begin{array}{c}\text { Palatali- } \\
\text { viga }\end{array}$ & $\begin{array}{c}\text { St. } \\
\text { seeritud }\end{array}$ & vahe & $p$ & $\mathbf{R}^{2}$ \\
\hline /o/ & Tagaosa kõrgus & 8,7 & 0,65 & 14,3 & 0,47 & 5,6 & $<0,001$ & 0,876 \\
& Eesosa kõrgus & 6,5 & 0,89 & 4,5 & 0,43 & 2,0 & $<0,001$ & 0,894 \\
& Keskosa eespoolsus & $-16,8$ & 1,63 & $-12,9$ & 0,41 & 3,9 & $<0,001$ & 0,958 \\
\hline /u/ & Tagaosa kõrgus & 8,2 & 0,64 & 14,0 & 0,47 & 5,8 & $<0,001$ & 0,876 \\
& Eesosa kõrgus & 6,9 & 0,89 & 5,2 & 0,42 & 1,7 & $<0,001$ & 0,894 \\
& Keskosa eespoolsus & -17 & 1,63 & $-13,8$ & 0,41 & 3,2 & $<0,001$ & 0,958 \\
\hline
\end{tabular}

Märkus. Tabelis on esitatud mudeli prognoositud väärtused ja standardvead (st. viga) vastavalt palataliseerimata ja palataliseeritud sõnades. Post hoc testi põhjal on välja toodud palatalisatsiooni efekti suurus (vahe) ning statistiline olulisus $(p)$. Mudeli üldist kirjeldusvõimet näitab determinatsioonikordaja $\left(\mathrm{R}^{2}\right)$. 


\subsection{Palatalisatsiooni mõju vokaalide ja /l/-i hääldusele}

Joonisel 4 on kujutatud vokaalide $/ \mathrm{a} / \mathrm{ja} / \mathrm{u} / \mathrm{ja}$ neile järgneva $/ \mathrm{l} / \mathrm{i}$ häälduskontuurid ning tabelites 6 ja 7 on esitatud statistiliste mudelite väljundite kokkuvõtted. Tabelitest 6 ja 7 näeme, et mudelite kirjeldusvõime jäi vahemikku $85-96 \%$. Analüüsitud sõnades oli /a/ kontekstis sõnaalguline konsonant $\mathrm{kas} / \mathrm{t} / \mathrm{h} / \mathrm{m} /$ või $/ \mathrm{h} / ; / \mathrm{u} /$ kontekstis oli sõna alguses $/ \mathrm{m} /$.
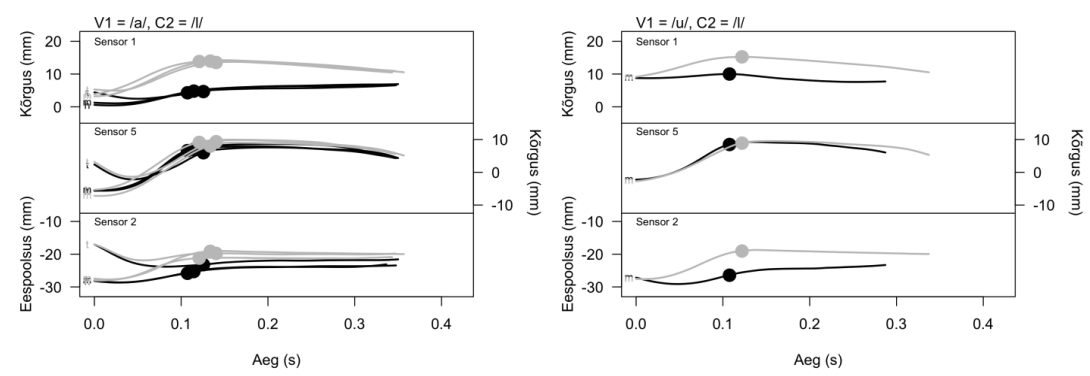

Joonis 4. Keele tagaosa (sensor 1) ja eesosa (sensor 5) kõrgus ning keele eespoolsus (sensor 2, millimeetrites hammaste lõikejoone suhtes) vokaali ja konsonandi /1/ hääldamise vältel. Musta joonega on tähistatud palataliseerimata, halliga palataliseeritud sõnad. Kontuurjoonte ees on tähega tähistatud sõna alguskonsonant. Ring joonel tähistab häälikupiiri vokaali ja konsonandi vahel.

Keele tagaosa oli vokaalide hääldamisel enne palataliseeritud /1/-i kõrgem kui palataliseerimata /1/-i ees (mõlema vokaali puhul on $p<0,001)$. Keele eesosa oli /a/ hääldamisel enne palataliseeritud $/ 1 /-\mathrm{i}$ kõrgem $(p<0,001)$, kuid $/ \mathrm{u} /$ hääldamisel mitte $(p=0,110)$. Keele eesosa oli mõlema vokaali hääldamisel enne palataliseeritud /1/-i eespoolsem kui palataliseerimata $/ 1 /$-i ees $(p<0,001)$. 
Tabel 6. Kokkuvõte üldistatud aditiivse segamudeli väljunditest keele liikumise kohta (millimeetrites) /1/-ile eelneva vokaali hääldamisel.

\begin{tabular}{llrrrrrrr}
\hline V1 & C2 $=/ \mathbf{l} /$ & $\begin{array}{c}\text { Palatali- } \\
\text { seerimata }\end{array}$ & $\begin{array}{c}\text { St. } \\
\text { viga }\end{array}$ & $\begin{array}{c}\text { Palatali- } \\
\text { seeritud }\end{array}$ & $\begin{array}{c}\text { St. } \\
\text { viga }\end{array}$ & Vahe & $p$ & $\mathbf{R}^{2}$ \\
\hline /a/ & Tagaosa kõrgus & 2,8 & 0,65 & 8,8 & 0,46 & 6,0 & $<0,001$ & 0,925 \\
& Eesosa kõrgus & $-0,1$ & 0,82 & 0,9 & 0,22 & 1,0 & $<0,001$ & 0,851 \\
& Keskosa eespoolsus & $-25,5$ & 1,69 & $-23,2$ & 0,35 & 2,3 & $<0,001$ & 0,901 \\
\hline$/ \mathbf{u} /$ & Tagaosa kõrgus & 9,3 & 0,65 & 12,7 & 0,46 & 3,4 & $<0,001$ & 0,925 \\
& Eesosa kõrgus & 2,1 & 0,82 & 2,4 & 0,23 & 0,4 & 0,110 & 0,851 \\
& Keskosa eespoolsus & $-28,2$ & 1,68 & $-24,0$ & 0,35 & 4,2 & $<0,001$ & 0,901 \\
\hline
\end{tabular}

Märkus. Tabelis on esitatud mudeli prognoositud väärtused ja standardvead (st. viga) vastavalt palataliseerimata ja palataliseeritud sõnades. Post hoc testi põhjal on välja toodud palatalisatsiooni efekti suurus (vahe) ning statistiline olulisus $(p)$. Mudeli üldist kirjeldusvõimet näitab determinatsioonikordaja $\left(\mathrm{R}^{2}\right)$.

Keele tagaosa oli palataliseeritud /1/-i hääldamisel vokaalide kontekstis kõrgem kui palataliseerimata /1/-i puhul (nii /a/ kui /u/ kontekstis oli $p<0,001)$. Keele eesosa oli /a/ kontekstis kõrgem $(p<0,001)$, kuid /u/ kontekstis mitte $(p=0,692)$. Keele keskosa, ja seega kogu keel tervikuna, oli mõlema vokaali kontekstis eespoolsem (mõlema puhul oli $p<0,001)$.

Tabel 7. Kokkuvõte üldistatud aditiivse segamudeli väljunditest keele liikumise kohta (millimeetrites) /1/-i hääldamisel.

\begin{tabular}{llrrrrrrr}
\hline V1 & C2 $=/ \mathbf{l} /$ & $\begin{array}{c}\text { Palatali- } \\
\text { seerimata }\end{array}$ & $\begin{array}{c}\text { St. } \\
\text { viga }\end{array}$ & $\begin{array}{c}\text { Palatali- } \\
\text { seeritud }\end{array}$ & $\begin{array}{c}\text { St. } \\
\text { viga }\end{array}$ & Vahe & $p$ & $\mathbf{R}^{2}$ \\
\hline /a/ & Tagaosa kõrgus & 6,3 & 0,67 & 12,6 & 0,54 & 6,3 & $<0,001$ & 0,924 \\
& Eesosa kõrgus & 7,4 & 0,82 & 8,6 & 0,28 & 1,2 & $<0,001$ & 0,896 \\
& Keskosa eespoolsus & $-23,2$ & 1,64 & $-20,2$ & 0,52 & 3,0 & $<0,001$ & 0,959 \\
\hline /u/ & Tagaosa kõrgus & 8,4 & 0,67 & 13,2 & 0,55 & 4,8 & $<0,001$ & 0,924 \\
& Eesosa kõrgus & 8,3 & 0,82 & 8,5 & 0,28 & 0,2 & 0,692 & 0,896 \\
& Keskosa eespoolsus & $-24,4$ & 1,64 & $-19,3$ & 0,52 & 5,1 & $<0,001$ & 0,959 \\
\hline
\end{tabular}

Märkus. Tabelis on esitatud mudeli prognoositud väärtused ja standardvead (st. viga) vastavalt palataliseerimata ja palataliseeritud sõnades. Post hoc testi põhjal on välja toodud palatalisatsiooni efekti suurus (vahe) ning statistiline olulisus $(p)$. Mudeli üldist kirjeldusvõimet näitab determinatsioonikordaja $\left(\mathrm{R}^{2}\right)$. 


\subsection{Palatalisatsiooni mõju vokaalide ja /n/-i hääldusele}

Joonisel 5 on kujutatud vokaalide /a/ ja /o/ ja neile järgneva konsonandi /n/-i häälduskontuurid ning tabelites 8 ja 9 on esitatud statistiliste mudelite väljundite kokkuvõtted. Tabelitest 8 ja 9 näeme, et mudelite kirjeldusvõime jäi vahemikku 95-98\%. Vokaali /a/ kontekstis oli sõna alguses konsonant /k/, /o/ kontekstis oli vokaal esimene häälik.
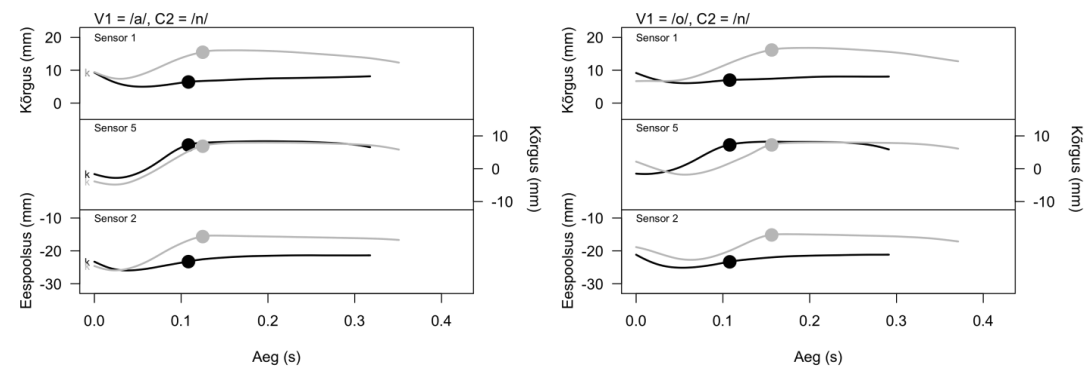

Joonis 5. Keele tagaosa (sensor 1) ja eesosa (sensor 5) kõrgus ning keele eespoolsus (sensor 2, millimeetrites hammaste lõikejoone suhtes) vokaali ja konsonandi /n/ hääldamise vältel. Musta joonega on tähistatud palataliseerimata, halliga palataliseeritud sõnad. Kontuurjoonte ees on tähega tähistatud sõna alguskonsonant. Ring joonel tähistab häälikupiiri vokaali ja konsonandi vahel.

Keele tagaosa oli vokaalide hääldamisel enne palataliseeritud /n/-i kõrgem kui palataliseerimata /n/-i ees (mõlema vokaalikonteksti puhul $p<0,001)$. Keele eesosa oli /a/ hääldamisel madalamal $(p<0,001)$, kuid $/ \mathrm{u} /$ hääldamisel ei olnud kahel konditsioonil vahet $(p=0,192)$. Keele keskosa oli vokaalide hääldamisel enne palataliseeritud $/ \mathrm{n} /$-i eespoolsem (nii /a/ kui ka /o/ puhul oli $p<0,001$ ) kui enne palataliseerimata /n/-i. 
Tabel 8. Kokkuvõte üldistatud aditiivse segamudeli väljunditest keele liikumise kohta (millimeetrites) /n/-ile eelneva vokaali hääldamisel.

\begin{tabular}{llrrrrrrr}
\hline V1 & $\mathbf{C 2}=/ \mathbf{n} /$ & $\begin{array}{c}\text { Palatali- } \\
\text { seerimata }\end{array}$ & $\begin{array}{c}\text { St. } \\
\text { viga }\end{array}$ & $\begin{array}{c}\text { Palatali- } \\
\text { seeritud }\end{array}$ & $\begin{array}{c}\text { St. } \\
\text { viga }\end{array}$ & Vahe & $p$ & $\mathbf{R}^{2}$ \\
\hline /a/ & Tagaosa kõrgus & 6,0 & 0,73 & 10,6 & 0,37 & 4,6 & $<0,001$ & 0,944 \\
& Eesosa kõrgus & 0,7 & 1,06 & $-0,6$ & 0,46 & 1,3 & 0,018 & 0,949 \\
& Keskosa eespoolsus & $-24,8$ & 1,78 & $-21,5$ & 0,61 & 3,3 & $<0,001$ & 0,974 \\
\hline /o/ & Tagaosa kõrgus & 6,8 & 0,73 & 10,1 & 0,37 & 3,3 & $<0,001$ & 0,944 \\
& Eesosa kõrgus & 1,8 & 1,06 & 1,2 & 0,46 & 0,6 & 0,192 & 0,949 \\
& Keskosa eespoolsus & -24 & 1,78 & $-19,5$ & 0,61 & 4,5 & $<0,001$ & 0,974 \\
\hline
\end{tabular}

Märkus. Tabelis on esitatud mudeli prognoositud väärtused ja standardvead (st. viga) vastavalt palataliseerimata ja palataliseeritud sõnades. Post hoc testi põhjal on välja toodud palatalisatsiooni efekti suurus (vahe) ning statistiline olulisus $(p)$. Mudeli üldist kirjeldusvõimet näitab determinatsioonikordaja $\left(\mathrm{R}^{2}\right)$.

Keele tagaosa oli palataliseeritud /n/-i hääldamisel vokaalide kontekstis kõrgem kui palataliseerimata $/ \mathrm{n} /$-i puhul (mõlema vokaali puhul oli $p<0,001)$, kuid eesosa mitte (/a/ kontekstis oli $p=0,55$; /o/ kontekstis oli $p=0,842$ ). Keele keskosa oli /n/-i hääldamisel mõlema vokaali kontekstis eespoolsem $(p<0,001)$.

Tabel 9. Kokkuvõte üldistatud aditiivse segamudeli väljunditest keele liikumise kohta (millimeetrites) /n/-i hääldamisel.

\begin{tabular}{llrrrrrrr}
\hline V1 & $\mathbf{C 2}=/ \mathbf{n} /$ & $\begin{array}{c}\text { Palatali- } \\
\text { seerimata }\end{array}$ & $\begin{array}{c}\text { St. } \\
\text { viga }\end{array}$ & $\begin{array}{c}\text { Palatali- } \\
\text { seeritud }\end{array}$ & $\begin{array}{c}\text { St. } \\
\text { viga }\end{array}$ & Vahe & $p$ & $\mathbf{R}^{\mathbf{2}}$ \\
\hline /a/ & Tagaosa kõrgus & 7,4 & 0,80 & 14,8 & 0,68 & 7,4 & $<0,001$ & 0,950 \\
& Eesosa kõrgus & 8,0 & 0,98 & 7,5 & 0,50 & 0,5 & 0,550 & 0,955 \\
& Keskosa eespoolsus & $-21,7$ & 1,86 & $-15,7$ & 0,78 & 6,0 & $<0,001$ & 0,980 \\
\hline /o/ & Tagaosa kõrgus & 7,7 & 0,80 & 15,6 & 0,68 & 7,9 & $<0,001$ & 0,950 \\
& Eesosa kõrgus & 7,8 & 0,96 & 7,5 & 0,50 & 0,3 & 0,842 & 0,955 \\
& Keskosa eespoolsus & $-21,7$ & 1,86 & $-15,1$ & 0,78 & 6,6 & $<0,001$ & 0,980 \\
\hline
\end{tabular}

Märkus. Tabelis on esitatud mudeli prognoositud väärtused ja standardvead (st. viga) vastavalt palataliseerimata ja palataliseeritud sõnades. Post hoc testi põhjal on välja toodud palatalisatsiooni efekti suurus (vahe) ning statistiline olulisus ( $p$ ). Mudeli üldist kirjeldusvõimet näitab determinatsioonikordaja $\left(\mathrm{R}^{2}\right)$. 


\subsection{Palatalisatsiooni mõju vokaalide ja konsonantide kestustele}

Joonisel 6 on näidatud konsonantidele eelnenud vokaalide kestused ja tabelis 10 nende keskmised väärtused.

Lineaarse segamudeli väljund näitas, et vokaali /o/ kestus oli enne palataliseeritud /n/-i pikem kui enne palataliseerimata vastet $(p<0,001)$. Muudel juhtudel ei olnud palatalisatsiooni mõju vokaali kestusele statistiliselt oluline.

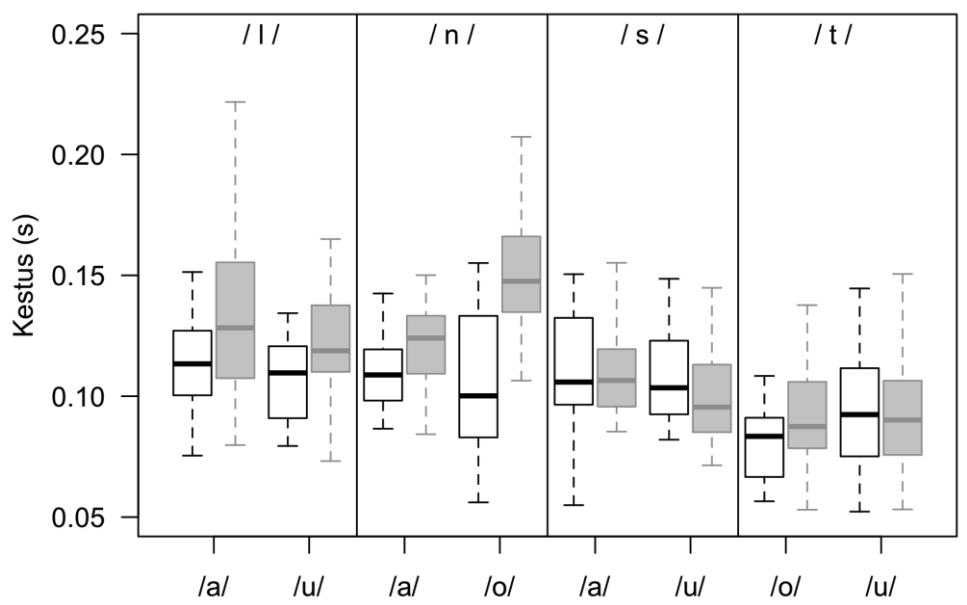

Joonis 6. Vokaalide kestus (sekundites) palataliseerimata (must) ja palataliseeritud (hall) konsonantide ees, rühmitatud vokaalile järgneva konsonandi põhjal.

Tabel 10. Vokaalide kestus (millisekundites) palataliseerimata ja palataliseeritud konsonantide kontekstis.

\begin{tabular}{lcccccccc}
\hline C2 & \multicolumn{2}{c}{$/ \mathbf{l} /$} & \multicolumn{2}{c}{$/ \mathbf{n} /$} & \multicolumn{2}{c}{$/ \mathbf{s} /$} & \multicolumn{3}{c}{$/ \mathbf{t} /$} \\
V1 & $/ \mathbf{a} /$ & $/ \mathbf{u} /$ & $/ \mathbf{a} /$ & $/ \mathbf{o} /$ & $/ \mathbf{a} /$ & $/ \mathbf{u} /$ & $/ \mathbf{o} /$ & $/ \mathbf{u} /$ \\
\hline Palataliseerimata & 117 & 108 & 108 & 108 & 108 & 108 & 81 & 95 \\
Palataliseeritud & 132 & 122 & 125 & 156 & 109 & 101 & 97 & 94 \\
Vahe & 15 & 14 & 17 & 48 & 1 & 7 & 16 & 1 \\
$p$ & 0,121 & 1 & 0,915 & $<0,001$ & 1 & 1 & 1 & 1 \\
\hline
\end{tabular}

Märkus. Välja on toodud palatalisatsioonist tingitud kestuse erinevus (vahe) ja post hoc testil põhinev statistilise olulisuse hinnang palatalisatsiooni efektile. 
Joonisel 7 on kujutatud konsonantide kestused, tabelis 11 on esitatud konsonantide keskmised kestused.

Lineaarse segamudeli väljund näitas, et palataliseeritud /1/-i kestus pärast /u/-d oli pikem kui palataliseerimata vaste puhul $(p<0,01)$. Muudel juhtudel ei olnud palatalisatsioonist tingitud kestuslikud erinevused statistiliselt olulised.

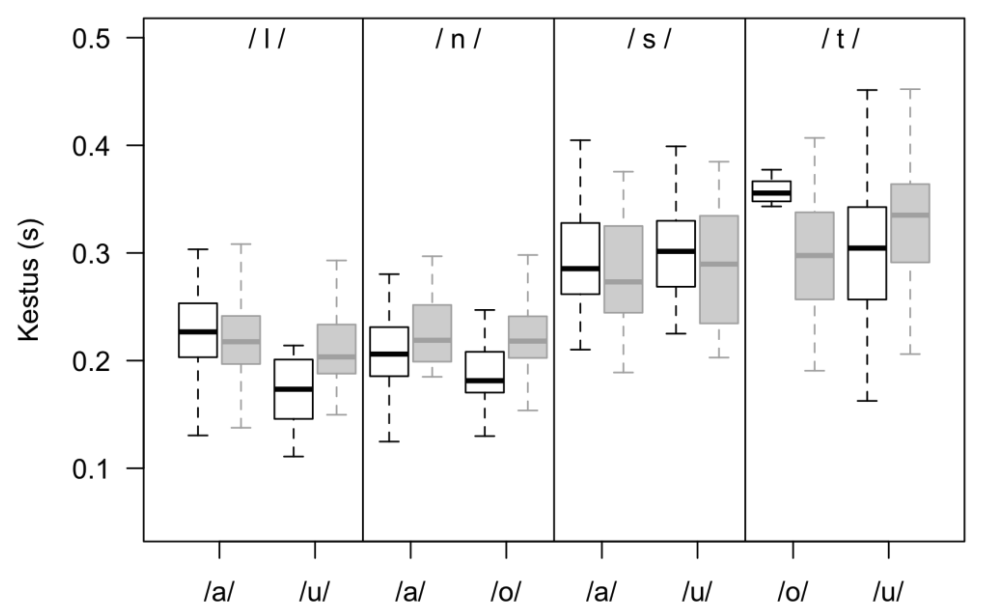

Joonis 7. Vokaalide kestus (sekundites) palataliseerimata (must) ja palataliseeritud (hall) konsonantide ees, rühmitatud vokaalile järgneva konsonandi põhjal.

Tabel 11. Konsonantide kestus (millisekundites), rühmitatud eelneva vokaali konteksti ja palatalisatsiooni järgi.

\begin{tabular}{lcccccccc}
\hline $\mathbf{C 2}$ & \multicolumn{2}{c}{$/ \mathbf{l} /$} & \multicolumn{2}{c}{$/ \mathbf{n} /$} & \multicolumn{2}{c}{$/ \mathbf{s} /$} & \multicolumn{2}{c}{$/ \mathbf{t} /$} \\
V1 & $/ \mathbf{a} /$ & $/ \mathbf{u} /$ & $/ \mathbf{a} /$ & $/ \mathbf{0} /$ & $/ \mathbf{a} /$ & $/ \mathbf{u} /$ & $/ \mathbf{o} /$ & $/ \mathbf{u} /$ \\
\hline Palataliseerimata & 228 & 180 & 209 & 183 & 299 & 302 & 346 & 299 \\
Palataliseeritud & 218 & 215 & 226 & 215 & 291 & 290 & 300 & 328 \\
Vahe & 10 & 35 & 17 & 32 & 8 & 12 & 46 & 29 \\
$p$ & 1 & 0,010 & 1 & 0,175 & 1 & 1 & 1 & 0,517 \\
\hline
\end{tabular}

Märkus. Välja on toodud palatalisatsioonist tingitud kestuse erinevus (vahe) millisekundites ning post hoc testil põhinev statistilise olulisuse hinnang palatalisatsiooni efektile. 


\section{Diskussioon}

Uurimistulemused näitasid, et palataliseerimine mõjutas konsonandi ja sellele eelneva vokaali häälduskohta ja -viisi. Palataliseerimisega kaasnes konsonandi ja eelneva vokaali hääldamisel kõrgem ja eespoolsem keele asend. See on kooskõlas varasemate akustiliste uurimustega, mis raporteerivad palatalisatsiooniga kõrgemat $\mathrm{F} 2$ väärtust (Chiosáin ja Padgett 2012, Lehiste 1965, Liiv 1965b, Teras ja Pajusalu 2014 ning Vihman 1967), ning palatograafiliste uurimustega, mis raporteerivad /1/-i ja /n/-i hääldamisel keele laiemat kontaktala alveoolil ja mõlema vokaali eespoolsemat häälduskohta (Ariste 1943 ja Eek 1971). Erinevalt varasematest uurimustest (Ariste 1943, Kochetov 2002 ning Zygis ja Pompino-Marschall 1999) leidsime, et palataliseeritud /s/-i ja /t/ häälduskoht on samuti eespoolsem, mitte tagapoolsem. See vastuolu on ilmselt näiline ning tingitud erinevast mõõtmismeetodist: varasemad katsed on palatograafilised ning kirjeldavad suulael keele kontaktala, mis palataliseerimisel laieneb tahapoole. Käesolevas uurimuses on vaadeldud aga keele asendit. Keel üldiselt liigub ettepoole, kuid keeleselg tõuseb, mistõttu arvatavasti keeleselja ja suulae kontaktala laieneb tahapoole.

Erinevused tulemustes keele eesosa asendi kohta võivad olla tingitud artikulatsiooni üldisest varieeruvusest ja sõltuda kõneleja hääldusstrateegia valikust. Vastandlikud tulemused võivad olla põhjustatud ka sellest, et palatograafilistes uurimustes oli keelejuhtide arv piiratud ja seetõttu ei saadud võtta arvesse kõnelejatevahelist varieerumist.

Analüüsist selgus, et palataliseerimise mõju keele eesosa kõrgusele ei olnud nii süsteemne kui keele tagaosa kõrgusele ja keele eespoolsusele. Tundus, et mõju varieerus konsonandi häälduskohast sõltuvalt. Näiteks ei mõjutanud palatalisatsioon /n/-i ja talle eelnevate vokaalide häl̈ldamisel keele eesosa kõrgust. ///-i ja talle eelneva /a/ kontekstis oli keele eesosa kõrgem, kuid /u/ kontekstis mitte. Palataliseeritud/t/ ja talle eelneva /o/ hälaldamisel oli keele eesosa madalam, /u/ kontekstis oli keele eesosa madalam ainult konsonandi hääldamisel. /s/-i puhul oli keele eesosa /u/ kontekstis madalam, /a/ kontekstis mitte. Keele eesosa kõrgus näitab, kas keeletipp on kõrge keele tagaosa asendiga allapoole suunatud või mitte. Antud juhul ei olnud tulemused piisavalt süsteemsed, et nende põhjal midagi lõplikku väita. Selge süsteemi puudumist võis mõjutada see, et mõni keelejuht kippus hoidma suud üsna kinnisena 
ja liigutas keelt nii vähe kui võimalik, sest kartis, et sensorid tulevad lahti. Kõnelejaid küll instrueeriti sensoritele mitte tähelepanu pöörama ja rääkima nii loomulikult kui võimalik, kuid sellegipoolest oli mõni tagasihoidlikum kui teine.

Kuigi käesolevas uurimuses ei analüüsitud sõnaalgulise konsonandi mõju palataliseeritud konsonandile eelneva vokaali ja konsonandi enda häälduskohale, on joonistelt näha, et näiteks /t/ kontekstis on / $\mathrm{u} /$ hääldamisel keele eesosa asend pärast/r/-i kõrgem kui pärast /n/-i. Paistis ka, et vokaalide hääldamisel on keel juba hääliku algusest enne palataliseeritud konsonanti kõrgem. Kuna rääkides soovitakse saavutada nii teadlikult kui ka alateadlikult ökonoomsust, siis kohendatakse artikulaatoreid nii, et need läbiksid hääldamisel sihtkohad optimaalselt lähedalt ja kiiresti (Šimko ja Cummings 2009).

Varasematest uurimustest on teada, et konsonandi palataliseerimisel pikeneb talle eelneva lühikese vokaali kestus (Lehiste 1965, Liiv 1965a ning Teras ja Pajusalu 2014). Käesoleva uurimuse tulemused seda kinnitada ei saa. Konsonandi kestus ei olnud samuti palatalisatsioonist süsteemselt mõjutatud ja varieerus. Selle ebakorrapärasuse võis osalt põhjustada ka katsesõnade valik ja rõhu asukoht raamlauses. Katsesõnadeks olid valitud eesti keeles tähendust omavad sõnad, kuid nii moodustuvad palatalisatsiooni minimaalpaarid sõnadest, kus üks paariline on funktsioonisõna (näiteks kas, kus) ja teine sisusõna (kass, kuss), mistõttu ei ole nad häälduses võrdselt rõhutatud. Seda püüti kompenseerida nii, et paigutati funktsioonisõnad kontrastiivfookust kandvasse positsiooni. Kuna raamlaused olid moodustatud selliselt, et katsesõna palataliseeritus oleks edasi antud lause kontekstiga, siis ei sattunud katsesõnad alati lause rõhu poolest võrdsesse positsiooni.

Eesti keele palatalisatsiooni on tavaks kirjeldada prepalatalisatsioonina, mille põhiline ja kõige olulisem tunnus on $i$-line siire eelneva vokaali ja palataliseeritud konsonandi vahel (Lehiste 1965, Liiv 1965a ning Teras ja Pajusalu 2014). Käesolevas uurimuses kogutud artikulograafiandmed näitavad, et kõrgem ja eespoolsem häälduskoht säilib läbivalt palataliseeritud konsonandile eelneva vokaali jooksul ja kestab kuni konsonandi lõpuni. See viitab sellele, et palatalisatsiooni mõju ulatub eelnevast vokaalist kaugemale ja $i$-line siire pole ainus palatalisatsiooni kirjeldav tunnus. Eesti keele kohta on varem väidetud, et konsonantühendis rakendub palatalisatsioon ainult 
esimesele komponendile (Ariste 1953: 78). Katse käigus salvestasime ka CVCC-struktuuriga sõnu, mis jäid küll käesoleva artikli materjalist välja, kuid mis on kavas võtta tähelepanu alla edaspidi, et kaardistada palatalisatsiooni mõju ka palataliseeritud hälikule järgnevale kontekstile.

\title{
5. Kokkuvõte
}

Käesolevas artiklis tutvustati elektromagnetartikulograafi abil saadud uurimistulemusi palatalisatsiooni mõju kohta keele asendile eestikeelsetes ühesilbilistes CVC:-struktuuriga sõnades. Tulemused näitasid, et konsonandi palataliseerimisega kaasnes kõikide palataliseeritud konsonantide ja neile eelnevate vokaalide hääldamisel kõrgem ja eespoolsem keele asend. Keele eesosa asendi kohta saadud tulemusetes selget süsteemi ei paistnud olevat. Näiteks ei mõjutanud palatalisatsioon keele eesosa kõrgust /n/-i ja talle eelnevate vokaalide hääldamisel. /1/-i ja talle eelneva /a/ hääldudkontekstis oli keele eesosa kõrgem, kuid /u/ kontekstis mitte. Palataliseeritud $/ \mathrm{t} / \mathrm{ja}$ talle eelneva /o/ hääldamisel oli keele eesosa madalam, /u/ kontekstis oli see madalam ainult konsonandi hääldamisel. Palataliseeritud /s/-i hääldamisel /u/ kontekstis oli keele eesosa madalam, /a/ kontekstis mitte. Konsonantide ja neile eelnevate vokaalide kestustes ei leitud süstemaatilist palataliseerimisest tingitud efekti. Ainult kahel juhul tõi palatalisatsioon kaasa pikema kestuse: vokaali /o/ hääldamisel /n/-i kontekstis ja /1/-i hääldamisel /u/ kontekstis.

\section{Tänuavaldus}

Autorid soovivad tänada katseisikuid motiveeritud osalemise eest.

\author{
Aadressid: \\ Anton Malmi \\ Tartu Ülikool \\ Eesti ja üldkeeleteaduse instituut \\ Jakobi 2 \\ 51014 Tartu, Eesti \\ E-mail: anton.malmi@ut.ee
}




\author{
Pärtel Lippus \\ Tartu Ülikool \\ Eesti ja üldkeeleteaduse instituut \\ Jakobi 2 \\ 51014 Tartu, Eesti \\ E-mail: partel.lippus@ut.ee
}

\title{
Kirjandus
}

Alumäe, Tanel, Ottokar Tilk ja Asadullah (2018) „Advanced rich transcription system for Estonian speech“. Rmt-s Kadri Muischnek ja Kaili Müürisep, toim. Human language technologies - the Baltic perspective. Proceedings of the Eighth International Conference Baltic HLT 2018, 1-8. Amsterdam: IOS Press.

Ariste, Paul (1943) Katselisfoneetilisi tähelepanekuid. Mit einem Referat: Experimentalphonetische Beobachtungen. (Acta Universitatis Tartuensis (Dorpatensis), B, Humaniora, 50.2) Tartu.

Ariste, Paul (1953) Eesti keele foneetika. Tallinn: Eesti Riiklik Kirjastus.

Barry, Martin C. (1992) „Palatalisation, assimilation and gestural weakening in connected speech“. Speech Communication 11, 4-5, 393-400.

Bateman, Nicoleta (2007) A crosslinguistic investigation of palatalization. San Diego: University of California.

Bates, Douglas, Martin Maechler, Ben Bolker ja Stewen Walker (2015) „Fitting linear mixed-effects models using Lme4“. Journal of Statistical Software 67, 1, 1-48.

Boersma, Paul ja David Weenink (2019) Praat: doing phonetics by computer [Computer program]. Version 6.1. Kättesaadav aadressil <http://www.praat.org/>. Alla laetud 13.07.2019.

Chiosáin, Máire Ní ja Jaye Padgett (2012) „An acoustic and perceptual study of connemara Irish palatalization“. Journal of the International Phonetic Association 42, 2 , 171-91.

Derkach, M., Gunnar Fant ja A. Serpa-Leitao (1970) „Phoneme coarticulation in Russian hard and soft VCV-utterances with voiceless fricatives“. STL-QPSR 11, 2-3, 1-7.

Eek, Arvo (1970) „Articulation of the Estonian sonorant consonants /n/ and /1/“". Eesti NSV Teaduste Akadeemia Toimetised. Ühiskonnateaduste Seeria 103-121.

Eek, Arvo (1971) „Articulation of the Estonian sonorant consonants. III. Palatalized [n] and [1]“. Eesti NSV Teaduste Akadeemia Toimetised. Ühiskonnateadused 20, 2 , 173-191.

Eek, Arvo (1972) „Acoustical description of the Estonian sonorant types“. Estonian Papers in Phonetics 1, 9-37.

Eek, Arvo (1973) „Observations in Estonian palatalization: an articulatory study“. Estonian Papers in Phonetics 2, 9-17.

Hothorn, Torsten, Frank Bretz ja Peter Westfall (2008) „Simultaneous Inference in General Parametric Models“. Biometrical Journal 50, 3, 346-63. 
Howie, Stephen M. (2001) „Formant transitions of Russian palatalized and nonpalatalized syllables“. IULC Working Papers 1, 1, 1-22.

Kask, Arnold (1972) Eesti keele ajalooline grammatika. Tartu: Tartu Riiklik Ülikool.

Kochetov, Alexei (2002) Production, perception, and emergent phonotactic patterns: a case of contrastive palatalization. New York ja London. Kättesaadav aadressil $<\mathrm{http}$ ://works.bepress.com/alexei_kochetov/8/>. Vaadatud 07.07.2019.

Kutser, Leida (1935) Eesti konsonantide palatogrammist. Seminaritöö. Tartu Ülikool.

Lehiste, Ilse (1965) „Palatalization in Estonian: some acoustic observations“. Rmt-s Viktor Kõressaar ja Aleksis Rannit, toim. Estonian poetry and language: studies in honor of Ants Oras, 136-162. Stockholm: Vaba Eesti.

Liiv, Georg (1965a) „Preliminary remarks on the acoustic cues for palatalization in Estonian“. Phonetics 13, 59-64.

Liiv, Georg (1965b) „Some experiments on the effect of vowel-consonant transitions upon the perception of palatalization in Estonian“. Soviet Fenno-Ugric Studies 1, $33-36$.

Malmi, Anton (2019) „Spectral characteristics of Estonian palatalization“. Rmt-s Sasha Calhoun, Paola Escudero, Marija Tabain ja Paul Warren, toim. Proceedings of the 19th International Congress of Phonetic Sciences, Melbourne, Australia 2019, 3782-3786. Canberra, Australia: Australasian Speech Science and Technology Association Inc.

Meister, Einar ja Stefan Werner (2015) „Comparing palatography patterns of Estonian consonants across time“. Proceedings of the 18th International Congress of Phonetic Sciences (ICPhS 2015), [1-5].

Piits, Liisi ja Mari-Liis Kalvik (2019) „Palatalisatsioon ühesilbilistes i-tüvelistes pika vokaaliga sõnades“. Keel ja Kirjandus 7, 513-533.

Põld, Enel (2016) Pika vokaali järgse konsonandi hääldus i-tüvelistes sõnades Eesti murretes. Bakalaureusetöö. Tartu.

Purcell, E. T. (1979) „Formant frequency patterns in Russian VCV utterances“. The Journal of the Acoustical Society of America 66, 6, 1691-1702.

RStudio Team (2019) Integrated development environment for $R$. [Computer software]. Boston, MA. Version 3.4.0. Kättesaadav aadressil <http://www.rstudio.org/>. Alla laetud 13.07.2019.

Šimko, Juraj ja Fred Cummings (2009), ,Sequencing of articulatory gestures using cost optimization“. Proceedings of Interspeech 2009, 60-63.

Teras, Pire ja Karl Pajusalu (2014) „Palatalisatsioonist ja prepalatalisatsioonist spontaanses eesti keeles“. Keel ja Kirjandus 4, 257-269.

Vihman, Marylin M. (1967) „Palatalization in Russian and Estonian“. Project on Linguistic Analysis Reports, Phonology Laboratory, Second Series 1, V1-32. University of California at Berkeley.

Wood, Simon N. (2017) Generalized additive models: an introduction with R. 2nd ed. Boca Raton, London ja New York: CRC Press.

Zygis, Marzena ja Bernd Pompino-Marschall (1999) „The articulation of secondarily palatalized coronals in Polish“. Proceedings of the 14th International Congress of Phonetic Sciences (ICPhS 1999), 1987-1900. 


\begin{abstract}
Anton Malmi and Pärtel Lippus: The position of the tongue in Estonian palatalization. This article analyses the effect of secondary palatalization of alveolar consonants on the place of articulation and the segmental duration in Estonian CVC words. The study was carried out with 21 test subjects using a Carstens AG501 electromagnetic articulograph. The results show that the place of articulation of palatalized consonants was always higher and more anterior than that of non-palatalized consonants. The back of the tongue was raised towards the hard palate, but the height of the apical part of the tongue was not systematically affected by palatalization. With few exceptions, the duration of the vowels and consonants were not affected by palatalization.
\end{abstract}

Keywords: articulatory phonetics, experimental phonetics, articulation, palatalization, Estonian, duration, Carstens AG501 


\section{Lisa 1. Analüüsis kasutatud laused}

1_kas Ta küsis minult kas, mitte kus ma töötanud olen.

2_kass Mul oli punane kass, mitte must.

3_kus Tahtsin teada kus, mitte kas sul töö on.

4_kuss Palun ole kuss, mitte ära räägi kogu aeg.

5_tall Kevadel sündis väike tall, mitte vasikas.

6 tall Hobustele ehitati uus tall, mis pakub neile peavarju kogu aasta.

7_hall Külmal hommikul oli maas hall, mida oli ilus vaadata.

8_hall Minu auto on hall, mitte valge.

9 mall Mu sõbranna on Mall, mitte Anu.

10_mall Joonestamiseks on vajalik mall, mitte joonlaud.

11 mul See raamat oli mul, mitte sul.

12_mull Vee alt tuli pinnale mull, mis valjult lõhkes.

15_on Temas see miski on, mida ma ei oska kirjeldada.

16_onn Mul oli metsas onn, mida ma ehitasin terve suve.

17_kann Kastmiseks on meil rauast kann, mida olen juba kaua kasutanud.

18_kann Mänguasja kohta öeldi vanasti kann, mitte lelu.

19_nutt Targal poisil oli silmapaistev nutt, mis teda elus edasi viis.

20 nutt Mul oli kurgus nutt, mida ma hästi varjasin.

21_kott Mul tuli jalast puidust kott, mis viis mu tasakaalust välja.

22_kott Maas lebas suur kott, mis jäi kõikidele ette.

55_rutt Tal on alati kuskile mujale rutt, mitte minu juurde.

56_rutt Tema nimi on Rutt, mitte Kadi. 